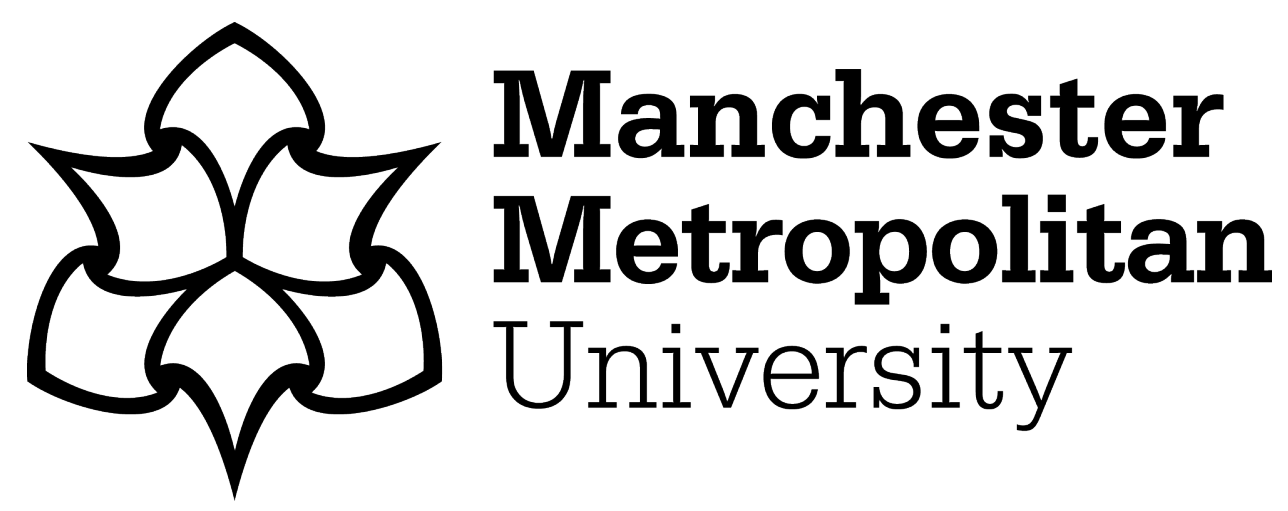

Szulc, Joanna, Davies, Julie ORCID logoORCID: https://orcid.org/00000002-6875-3100, Tomczak, Michael and McGregor, Frances (2021) AMO perspectives on the well-being of neurodivergent human capital. Employee Relations, 43 (4). pp. 858-872. ISSN 0142-5455

Downloaded from: https://e-space.mmu.ac.uk/627355/

Version: Accepted Version

Publisher: Emerald

DOI: https://doi.org/10.1108/ER-09-2020-0446

Please cite the published version 


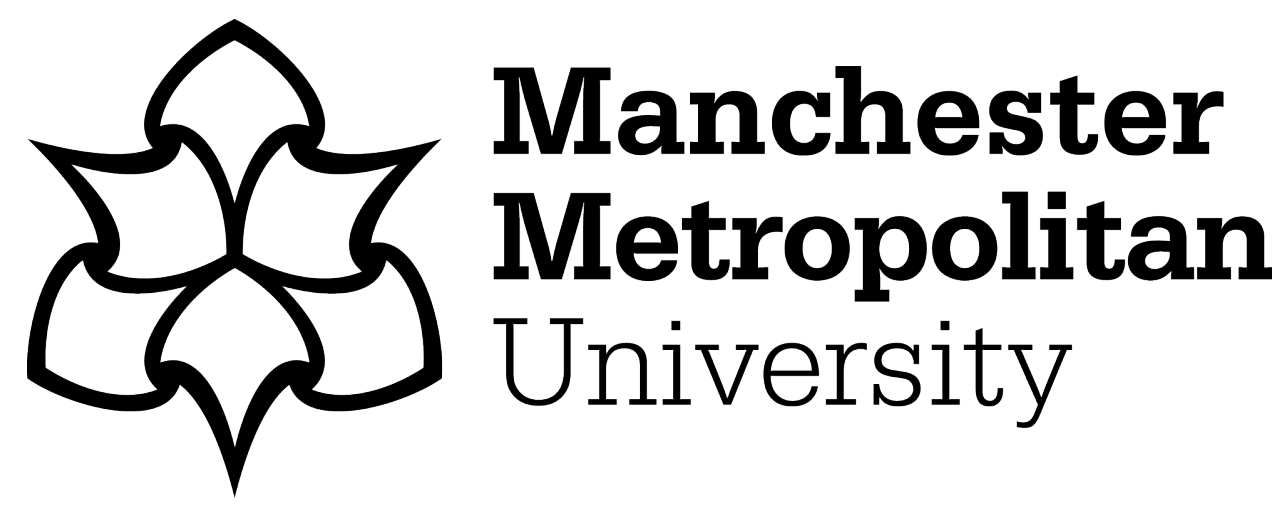

Szulc, Joanna and Davies, Julie and Tomczak, Michael and McGregor, Frances (2021) AMO perspectives on the well-being of neurodivergent human capital. Employee Relations. ISSN 0142-5455 (In Press)

Downloaded from: http://e-space.mmu.ac.uk/627355/

Version: ["content_typename_Accepted version" not defined]

Publisher: Emerald

Please cite the published version 


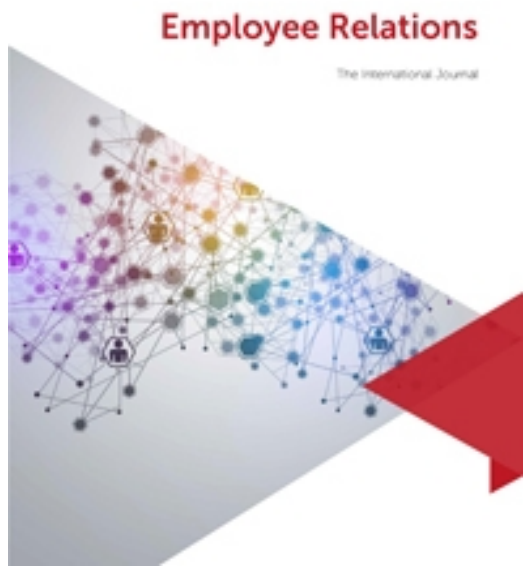

AMO perspectives on the well-being of neurodivergent human capital.

\begin{tabular}{|r|l|}
\hline Journal: & Employee Relations \\
\hline Manuscript ID & ER-09-2020-0446.R1 \\
\hline Manuscript Type: & Research Paper \\
\hline Keywords: & AMO Model, HR practices, Human capital, Neurodiversity, Well-being \\
\hline \multicolumn{2}{|l}{} \\
\hline
\end{tabular}




\title{
AMO perspectives on the well-being of neurodivergent human capital
}

\begin{abstract}
Purpose Existing management research and management practices frequently overlook the relationship between the above-average human capital of highly functioning neurodivergent employees, their subjective well-being in the workplace and performance outcomes. This paper calls for greater attention to the hidden human capital associated with neurodiversity by mainstreaming implementation of neurodiversity-friendly policies and practices.
\end{abstract}

Approach - Drawing on the ability, motivation and opportunity (AMO) framework, this conceptual paper integrates research on employee neurodiversity and well-being to provide a model of HR-systems level and human capital development policies, systems and practices for neurodivergent minorities in the workplace.

Findings - This paper illustrates that workplace neurodiversity, like biodiversity, is a natural phenomenon. For subjective individual psychological and organisational well-being, neurodivergent employees require an empathetic culture and innovative talent management approaches that respect cognitive differences.

Practical implications - The case is made for neurodivergent human capital development and policy-makers to promote inclusive employment and decent work in a context of relatively high unemployment for neurodivergent individuals.

Originality - This paper extends current debates on organisational equality, diversity and inclusion to a consideration of workplace well-being for highly functioning neurodivergent workers. It calls for more equitable and empathetic approaches to investing in employees with neurodevelopmental and cognitive disabilities.

Keywords AMO model, HR practices, Human capital, Neurodiversity, Well-being

Paper type Conceptual 


\section{Introduction}

Are you aware of the superpowers that are shared with Albert Einstein and theoretical physics, to Jennifer Aniston and acting, to Greta Thunberg and environmental activism? The common theme here is they are all neurodivergent. Neurodivergence refers to a natural range of differences in human brain functions in the workplace based on alternative thinking styles, such as attention deficit hyperactivity disorder (ADHD), autism, dyspraxia and dyslexia. Prominent companies are increasingly leveraging the above average abilities of high functioning neurodivergent employees as a source of human capital for competitive advantage (Krzeminska et al., 2019). This is because highly functioning neurodivergent individuals often possess unique abilities akin to human superpowers that are likely to make them excel in professional settings (Austin and Pisano, 2017). However, many organisations still unintentionally exclude or discard neurodivergent talent (Scott et al., 2019) based on innocent assumptions of employee homogeneity (Winterton and Cafferkey, 2019).

Indeed, neurodivergent employees are often barred from work opportunities and experience significant levels of employment exclusion (Knapp et al., 2009). Those who secure employment frequently experience isolation (Hedley et al., 2018), stigmatization (Müller et al., 2003), and stereotyping and biases (Maroto and Pettinicchio, 2015; Premeaux, 2001) with negative impact on their well-being and mental health (Mastroianni and Storberg-Walker, 2014) and disappointing employment outcomes (Tomczak, 2020). However, from a strengthsbased perspective, the problem does not lie with neurodivergent individuals but with the limited opportunities for engagement and growth (Johnson et al., 2020) and employment practices that fail to acknowledge that the concept of well-being is pluralistic (Hagner and Cooney, 2005; Krzeminska et al., 2019).

By providing a conceptual model underpinned by a literature review to explore how the abilities, motivations, and opportunities for neurodivergent individuals can be enhanced in the workplace, the article makes several contributions to existing employee relations literature. First, it takes neurological developments traditionally regarded as atypical and conceptualizes them as normal human variations (Jaarsma and Welin, 2012). By highlighting extraordinary knowledge, skills, and abilities offered by neurodivergent individuals, a nuanced and less obvious consideration of human capital that resides in a specific category of people is presented. Second, the well-established AbilityMotivation-Opportunity (AMO) framework is adopted in an adapted version (Kellner et al., 2019) to enhance our understanding of workplace well-being from the perspective of neurodivergent minorities. Third, this paper explains how perceptions of, and reactions to the same HR practices differ for neurodivgrgent and 
neurotypical employees. In doing so, it addresses the call by Cafferkey et al. (2019) to move away from universal HRM as a route to positive employee outcomes and it facilitates a more accurate reflection of organisational reality (see also: Kinnie et al., 2005) for disadvantaged members of society. Finally, while diversity management is a core competency for HR scholars (Bierema, 2010), the areas of study are largely limited to age, gender, and race with little emphasis paid to neurodevelopmental and cognitive disability (Procknow and Rocco, 2016). Our study adds to the existing limited research scrutinizing how neurodivergent human capital could be integrated into organisations and developed for organisational performance and employee satisfaction.

This paper is structured as follows. First, we discuss the literature review methodology and key debates on human capital and neurodiversity in organisational settings. Second, building on the dynamic AMO model, we investigate the abilities and motivations of neurodivergent individuals and consider what organisational practices can enhance these. Finally, we discuss implications for future research and practice.

\section{Literature review methodology}

To review the existing literature, we identified human capital, neurodiversity, and well-being studies in three ways. First, we engaged in a manual scan of leading HR and management journals rated two and above in the 2018 CABS Academic Journal Guide, journals in the field of developmental disabilities, professional body literature, and key textbooks. Second, we conducted a comprehensive web-based search of relevant themes (e.g., neurodiversity at work, neurodiversity and well-being) using several electronic databases (e.g., Business Source Premier, Web of Science, Google Scholar) covering the last three decades (1991-2021). Third, we further scanned the references lists from the articles identified through the first two methods. This strategy was aimed at the specific question: how can we support the well-being of neurodivergent human capital in the workplace? The subsequent analysis resulted in a development of a conceptual model of neurodivergent abilitiesmotivation-opportunities for HRM research. Importantly, we do not intend to be exhaustive with our model, but the constructs we chose illustrate possibilities for neurodiversity research.

\section{Human capital and neurodiversity}

Human capital generally describes the knowledge, skills, and attitudes that make employees assets to organisations (Beardwell and Thompson, 2017). This paper supports Winterton and Cafferkey's (2019) argument that human capital is preferable to human resources to conceptualise workers. Human resources are exploited for organisational advantage and human 
capital, which is owned by individual employees, needs to be invested in (Cappelli, 2020) by organisations. This perspective thus advocates creating opportunities for development (Garavan et al., 2001) and emphasises that the way in which human capital is managed is vital for organisational success (Davenport and Prusak, 1998).

To manage human capital, it is important to recognise that distinct categories of employees have different needs and require specific HRM practices to contribute to organisational performance (Kinnie et al., 2005). For instance, HR practices may have different effects based on employment modes (Lepak and Snell, 2002), occupational identities (Cafferkey et al., 2020), or employee demographic dissimilarity (Jiang et al., 2017). Clearly, existing human capital typologies are not designed to consider neurodevelopmental differences in the workplace. Accommodating the values and specific needs of neurodivergent individuals, however, should be high on organisational agenda since neurodivergent individuals represent in total over $10 \%$ of the overall population (CIPD, 2018). This, in turn, poses particular challenges for organisations and HR functions.

First, hiring processes still tend to define talent too narrowly (Krzeminska et al., 2019) and over-reliance on interviews introduces bias against neurodivergent people who adopt atypical forms of interaction (Patton, 2019). For instance, research highlighted difficulties with shared intentionality (Tomasello et al., 2005) and reciprocating nonverbal cues (García-Pérez et al., 2007). This, in turn, leads to what has been described by Heasman and Gillespie (2019: 911) as 'mutual misunderstanding' which can be further intensified in the interview situation. Partly as a result of such inappropriate organisational hiring practices, neurodivergent individuals become unemployed or underemployed, with estimates as high as $90 \%$ for the autistic minority group (Lever, 2016). Second major challenge is concerned with how neurodivergent talent could be integrated into organisations to overcome potential problems relating to difficulties with social interaction, stress control and maintenance of interpersonal relationships (Hedley et al., 2018). Such difficulties that neuro-minorities face may be further exacerbated in light of the COVID-19 crisis. More specifically, recent changes to working patterns and new modes of communication (Davies, 2020) may have a negative impact on job experience (Kelly and Senior, 2021) and may be particularly difficult to navigate and manage for individuals who experience difficulties with adapting to change (Annabi et al., 2019). In light of these challenges, we call to move away from employment perspectives that view diversity as 'the problem' and instead we suggest that the problem lies in inappropriate management of diversity (see also: Härtel and Fujimoto, 2015). 
Despite calls for more theoretical and empirical research on the inclusion of neurodivergent individuals into employment (Johnson et al., 2020), 90\% of HR professionals in the UK reported that they do not consider neurodiversity in their people management practices (CIPD, 2018). Similarly, we know little about the well-being of neurodivergent employees beyond studies that show autistic minority groups suffer disproportionately from under and unemployment (Lever, 2016) as well as social isolation (Hedley et al., 2018) with potentially detrimental effects on their mental health (Mastroianni and Storberg-Walker, 2014). Consistently, this paper highlights the impact of the ways in which human capital is managed in organisations in relation to wider issues of well-being for disadvantaged individuals and employers where there are particular workforce shortages.

\section{A dynamic model of neurodivergent AMO for HRM research}

In our consideration of neurodivergent human capital, we adapt the dynamic version of the AMO model introduced by Kellner et al. (2019) to understand how varying needs of neurodivergent individuals can be accounted for by tailored HR practices. The model clearly delineates individual-level ability and motivation, and systems-level practices that enhance or inhibit these variables. It also points our attention to opportunities that overlap individual and systems levels. Kellner et al. (2019) suggest that all dimensions of the model interact with each other as well as with performance.

The utility of this model in the context of neurodivergent human capital is based on its assumptions that individuals do not blindly conform to HR intentions and the emphasis placed on the role of individual characteristics in meeting organizationally-relevant goals. By elevating the role of individuals and their specific characteristics, the model appears particularly well suited to emphasise the need for diversified HRM systems that are capable of recognizing but also effectively utilising and further developing the specific skills that reside within neurodivergent individuals. In fact, HR practices have been associated with their ability to disrupt the vicious cycle of inequality (Audenaert et al., 2020). Consistently, adapting the dynamic version of the AMO model to the context of neurodivergent employees could help us not only to better utilise employees' skills (Boxall et al., 2019) but to adopt a multi-stakeholder perspective for mutual gains from HR (Troth and Guest, 2020).

Figure 1 illustrates the adapted dynamic model induced from the literature review. It relates to the abilities and motivation of neurodivergent employees at individual and system levels. It further includes opportunities designed to create an inclusive workplace environment 
where both neurodivergent but also neurotypical employees can thrive and equally contribute to organisational success.

---Insert Figure 1 around here---

\section{Abilities}

Ability is the essence of human capital (Winterton and Cafferkey, 2019). It relates to individuals' skills, the occupation-relevant knowledge contextualised in work processes, as well as effectiveness in social interactions. At an individual level, neurodivergent individuals are described as having cognitive functioning different from what is seen as standard (CIPD, 2018). While not all neurodivergent individuals are the same, it is generally accepted that there are common characteristics and behaviours for each group as shown in Table I.

---Insert Table I around here---

Analytical thinking and attention to detail by individuals with autism often make them successful in a variety of roles, specifically in the IT industry (Annabi and Locke, 2019). The ability of dyslexic and dyspraxic individuals to think innovatively is useful for individual employees and teams (Doyle, 2020). Individuals with ADHD have become successful entrepreneurs because of their extraordinary ability to multitask and remain calm under pressure (Antshel, 2018).

\section{Recruitment and selection}

To realize the above-average abilities of neurodivergent individuals, organisations would have to adjust their recruitment and selection processes to reflect a broader definition of talent. Traditional interviews may constitute a significant challenge for many neurodivergent individuals (Carrero et al., 2019). For instance, difficulties with making eye contact, stress control, or lack of confidence may be challenging in interview situations particularly for individuals with autism (Hagner, 2003). Austin and Pisano (2017) concluded that neurodivergent individuals are likely to earn lower scores in interviews than their less-talented neurotypical counterparts. Hands-on skills assessment over an extended period of time may be preferable (Annabi and Locke, 2019) and project-based assessment with more relaxed interactions should allow for candidates' capabilities to emerge (Hurley-Hanson et al., 2020; Patton, 2019).

\section{Training and development}

Effective training and development practices not only increase the skills abilities of employees but also help organisations to boost employees' morale (Jiang et al., 2012). In order to combat 
the difficulties neurodivergent employees face when processing social information, communicating, or adapting to changes (Johnson et al., 2020) organisations may consider developing special training initiatives to support their skills, e.g. on-the-job interpersonal skills training, skills coaches providing individualized support or team buddies who provide assistance with daily tasks and workload management.

\section{Motivation}

Motivation relates to an individual's willingness to use their abilities in a productive manner (Purcell et al., 2003). Strategies commonly used for motivating typical employees may not resonate well with their neurodivergent counterparts (Parr et al., 2013). In contrast with typical employees, individuals with autism spectrum disorders may be more motivated by menial and repetitive tasks and will find too much autonomy or skill variety as overwhelming (Doyle, 2020) while employees with ADHD are likely to be motivated only if the task is intrinsically interesting (Brown, 2017). Additionally, the prospective workplace challenges that neurodivergent employees face (see Table I) will often perpetuate stigmatizing and discriminatory practices against these individuals (HurleyHanson et al., 2020; Silvers, 2011) with a potentially negative effect on their motivation (Whelpley et al., 2020). Interestingly, the challenges associated with communication faced by some neurodivergent employees (Doyle, 2020), being less responsive to social and monetary rewards (Scot Van-Zeeland et al., 2010) and placing less emphasis on impression management (Chevallier et al., 2012) often lead to the false perception that neurodivergent employees are disengaged and unmotivated (Patton, 2019). In reality, however, neurodivergent individuals may differ in their social and communication skills and often struggle to have their needs met but they do not lack motivation (Morrison et al., 2020: 2-3).

\section{Communication enhancement}

Prior research proved the need to facilitate communication between neurodivergent employees and employers for motivational outcomes (Scott et al. 2015). Since electronically mediated forms of communicating based on non-direct and non-verbal contact can improve communication processes disturbed by the difficulties in social interaction and social reciprocity (Tomczak, 2020, Tomczak et al., 2020), HR can incorporate the use online communicators, chats, discussion forums and chatbots to their more formal internal communication strategy. Personal digital assistants could be further used as vocational support to reduce personal support needs on the job and improve motivation to perform (see: Gentry et al., 2015). Cross-organisational neurodiversity awareness training may also be implemented as 
there are positive links between disability awareness training and improved communication outcomes (Philips et al., 2016). Such programmes explore, for example, coworker resentment (Jones, 1997), health-focused leadership, creating an inclusive organisational climate and diversity-related HR practices (Boehm and Dwertmann, 2015).

\section{Job design}

Although the impact of job design on employee motivation is well established, not much is known on its impact on neurodiverse employees. Initial insights from the extant literature suggest that some neurodivergent employees who experience difficulties with demands of flexibility may benefit from a structured work environment (Scott et al., 2015). It is also suggested that combining consistent and predictable tasks with a job that matches the intrinsic interests of neurodivergent individuals may bring further motivational benefits (Goldfarb et al., 2019). Work environment should be also designed in a way that gives neurodivergent individuals feelings of relatedness to maintain motivation. Indeed, caring workplace relationships are known to enhance well-being (Szulc, 2020) and work is portrayed as an opportunity for positive social interaction for neurodivergent employees through day-to-day communication and ad-hoc social events (Hedley et al., 2018), especially in small-group settings (Dreaver et al., 2020). Finally, research emphasised the role of positive reinforcement on the motivation of neurodivergent individuals (Müller et al., 2003). Consistently, clear, regular and constructive feedback is likely to have a positive impact on employee's motivation to complete a task (see also: Dreaver et al., 2020).

\section{Opportunities}

Neurodivergent individuals frequently face obstacles that prevent them from using their skills effectively (Patton, 2019). A number of opportunities aimed at supporting specific areas where neurodivergent individuals face the greatest difficulties can support effective interpersonal communication, coping with stressful situations, or sensory sensitiveness. These must be ingrained in wider inclusive organisational culture (Shore et al., 2018) based on inclusive leadership (Randel et al., 2018) and perceiving neurodivergent individuals through the prism of their strength and competence as opposed to potential deficits (see also: Annabi and Locke, 2019). Such an environment should allow for the utilization of the possibilities created by diversity not only in the context of performanceincreasing effects (Roberge and van Dick, 2010) but in the context of enhanced well-being of neurodivergent individuals in the first place.

The subsequent sections introduce $\underset{8}{\operatorname{sific}}$ opportunities that could be adopted as potential solutions to the problematic areas identified. They comprise non-technological (e.g., 
Johnson et al, 2020, Dreaver et al., 2020, Hayward et al., 2019) as well as technology-based interventions (e.g., Tomczak, 2020, Walsh et al., 2016) used to maintain, increase, and improve the functional capabilities of individuals with disabilities.

\section{Use of technology}

Management scholars have started to recognize the opportunities for neurodivergent employees arising from digital technology development (Tomczak, 2020), specifically assistive technology (Tomczak, 2018). For instance, multi-sensor stress measurement tools and dedicated mobile applications can reduce their workplace stress (Tomczak et al., 2020). HR may further consider how digitized technologies can assist them with the development of a remote form of work which gained importance in light of the COVID-19 pandemics. For instance, research suggests that the use of virtual reality within the workplace context provides a predictable and stable environment (Mpofu et al., 2019) which is so much needed for neurodivergent individuals and can serve as a vocational support device.

\section{Physical work environment}

Successful employment for neurodivergent individuals requires modification of the physical work environment to meet the specific needs as a result of sensory sensitiveness (Hayward et al., 2019). A network of sensors and controllers dynamically customizing ambient environment parameters such as temperature, humidity, noise, smell, and sunlight exposure can reduce distracting factors negatively affecting work comfort and efficiency (Tomczak, 2020). Office space can be further rearranged according to the needs of neurodivergent employees by providing relaxation areas - chill rooms, avoiding flashy colors, enabling work with headphones. Research demonstrates how such practices could result in increased opportunities to use neurodivergent skills more effectively with associated positive effects on one's subjective well-being (Dreaver et al., 2020; Hedley et al., 2018).

\section{External relations}

Since few organisations have expertise in neurodiversity, they could build relations with experts such as government and non-for-profit organisations committed to supporting neurodivergent individuals. Building on a number of case studies of prominent organizations engaged in wider neurodiversity programs, Austin and Pisano (2017) demonstrated how such social partners can assist organisations with local employment regulations, assist with recruitment and selection, delivering training and ongoing support. 


\section{Discussion}

The aim of this paper was to show the increased importance of understanding the well-being of neurodivergent employees from the perspectives of human capital systems to enhance their abilities, motivations and opportunities in the workplace. The model developed in this paper emphasizes the need for talent and diversity management policies to incorporate more nuanced approaches pre-appointment and throughout the employee life cycle. The insights generated provide several theoretical and practical cues, which we discuss next.

\section{Theoretical implications}

Our first contribution pertains to providing a more nuanced and less obvious consideration of human capital that resides in a specific category of neurodivergent people. While we observe a tendency in research to move away from focusing on privileged workers as organizational assets (Ashley and Empson 2013) to acknowledge the contribution of disabled employees to organizational success (Luu, 2018), little is still known about the value of neurodivergent human capital. We therefore contribute to the emerging strength-based approach to mental disorders (Wiklund et al., 2020) and neurodiversity (Wiklund et al., 2018) where a focus is placed on a person's assets as opposed to weaknesses.

Second, we emphasize the need for examining the strengths of neurodivergent individuals and highlight potential adjustments. Our conceptual framework of interactions between individual and systems factors enables a better theoretical understanding of the conditions under which high performance of neurodivergent individuals could be achieved with associated positive impact on their well-being. We partly answer the calls for existing mainstream HRM research to stop treating employees as an undifferentiated mass (Jiang et al., 2017) and to acknowledge the importance of differentiated HRM practices that capture unique needs of different groups of employees (Cafferkey et al., 2020).

Third, while dominant HRM models focus largely on performance, we elevate the importance of employee well-being (Boxall et al., 2016; Guest, 2017). By providing a more nuanced understanding as to how employers can promote a customised well-being agenda while supporting the abilities and motivations of neurodivergent individuals and facilitating the opportunities for human capital development, we answer Troth and Guest's (2020) calls for multi-stakeholder perspectives to explore the scope for mutual gains from HRM. This, in turn, has several practical implications discussed in the subsequent sections. 


\section{Practical implications}

The conceptual model presented in this paper can assist HR practitioners in developing a comprehensive approach to skill-, motivation-, and opportunity-enhancing practices tailored at specific needs of neurodivergent individuals to generate mutual gains. We demonstrated that traditionally understood systems-level practices may constitute a significant challenge for individuals (Krzeminska et al., 2019) who vary in terms of their neurocognitive ability in comparison to a typical employee (Doyle, 2020). For instance, we suggested that traditional interviews should be de-emphasised in favour of more inclusive recruitment approaches reflecting a broader definition of talent (for practical examples see: Carrero et al., 2019). Such practices will facilitate realizing the above-average abilities of neurodivergent employees only if they are combined with inclusive work designs and environments embedded in the entire organization (Obeidat et al., 2016). Consistently, we advocated a number of accommodations designed to make a significant difference to the quality of working life of neurodivergent employees and to enable them to reach full potential. Accommodations such as sensory sensitive office space design, transparent work structure or clear communication channels are often cheap and simple to implement but can bring real value for all employees (see: CIPD, 2018) through ensuring high levels of job involvement and fulfilment (Torraco, 2005).

The expectations placed on line managers to be involved in HR practice (Harney and Cafferkey, 2014) point our attention to their important role in the process of carrying out the practices tailored at specific needs of neurodivergent employees. We argue that organizations should explore what it means to be 'an effective line manager of neurodiversity' (see: Richards et al., 2019: 1917). By providing necessary resources (such as awareness training), they are likely to enable line managers to act as neurodiversity-confident HRM agents aware of the talents that neurodivergent individuals bring to the business. Since successful mentoring and coaching relationships are commonly positively associated with employee development and performance outcomes (Kim et al., 2013), further support from job coaches, team buddies, and external parties may not only facilitate building on the neurodivergent talent and skills but also to provide a more holistic view on their well-being and mental health.

Organizations could further work with medical and psychology professionals to develop cross-organizational awareness training fostering understanding of neurodiversity among organizational members. Such activities are found to promote relationship building and increase support for neurodivergent employees (Johnson et al., 2020: 141) and to remove the stigma associated with their employment (Hidegh \& Csillag, 2013). 


\section{Future research directions}

Although the topic of neurodiversity is gaining attention among management (Krzeminska, 2019) and HR scholars (Johnson et al., 2020), the work in this area is largely atheoretical. Most research is interested in the effectiveness of particular workplace accommodations (e.g., Scott et al., 2019) but not in the underlying processes of desirable employment outcomes (see: Goldfarb et al., 2019). We, therefore, call for a wider use of theory to promote a more comprehensive understanding of how neurodiversity-friendly accommodations can be administered and how they help to achieve positive outcomes. As Vogus and Taylor (2018) suggest, using validated measures associated with diversity climate, psychological safety and inclusive leadership may be a good starting point. Similarly, extensive theories on work experience such as self-determination theory (Deci \& Ryan, 2012) or job characteristics model (Hackman, 1980) can address the style of management most adaptive for neurodivergent employees in terms of autonomy support, or other social variables that promote stability and well-being (Goldfarb et al., 2019).

Beyond understanding the process behind workplace accommodations for neurodivergent employees, there is an urgent need for future research to evaluate the effectiveness of such adjustments. As Doyle (2020) argues, further research in this area would enable us to see what particular adjustments work for different individuals and roles and what impact this may have on organizational performance and employee well-being.

To accurately address the challenges of neurodiversity and an increasingly challenging environment for employability and organisational sustainability (Bailey and Breslin, 2021), collaborative research between neurodiversity and organizational researchers may be particularly useful (Vogus and Taylor, 2018). Such interdisciplinary collaborations can lead to developing integrated and comprehensive solutions to the persistent problems faced by neurodivergent minorities. 


\section{References}

Annabi, H. and Locke, J. (2019), "A theoretical framework for investigating the context for creating employment success in information technology for individuals with autism", Journal of Management \& Organization, Vol. 25 No. 4, pp.499-515.

Antshel, K.M. (2018), "Attention Deficit/Hyperactivity Disorder (ADHD) and Entrepreneurship", Academy of Management Perspectives, Vol. 31 No. 2, pp.243-265.

Ashley, L. and Empson, L. (2013), "Differentiation and discrimination: understanding social class and social exclusion in leading law firms", Human Relations, Vol. 66 No. 2, pp.219-244.

Audenaert, M., Van der Heijden, B., Conway, N., Crucke, S. and Decramer, A. (2020), "Vulnerable workers' employability competences: the role of establishing clear expectations, developmental inducements, and social organizational goals", Journal of Business Ethics, Vol. 166 No. 3, pp.627-641.

Austin, R. D. and Pisano, G. P. (2017), "Neurodiversity as a competitive advantage", Harvard Business Review, Vol. 95 No. 3, pp.96-103.

Bailey, K. and Breslin, D. (2021), "The COVID-19 pandemic: what can we learn from past research in organizations and management?", International Journal of Management Reviews, Vol. 23 No 1, pp.3-6.

Beardwell, J. and Thompson, A. (2017), Human Resource Management: A Contemporary Approach. $8^{\text {th }}$ ed., Harlow: Pearson.

Bierema, L.L. (2010), "Resisting HRD's resistance to diversity", Journal of European Industrial Training, Vol. 34 No. 6, pp.565-576.

Boehm, S.A., and Dwertmann, D.J.G. (2015), "Forging a singleedged sword: facilitating positive age and disability diversity effects in the workplace through leadership, positive climates, and HR practices", Work, Aging and Retirement, Vol. 1 No. 1, pp.41-63.

Boxall, P., Guthrie, J.P. and Paauwe, J. (2016), "Editorial introduction: progressing our understanding of the mediating variables linking HRM, employee well-being and organisational performance", Human Resource Management Journal, Vol. 26 No. 2, pp.103-111.

Boxall, P., Huo, M.L. and Winterton, J. (2019), "How do workers benefit from skill utilisation and how can these benefits be enhanced?", Journal of Industrial Relations, Vol. 61 No. 5, pp.704-725.

Brown, T. E. (2017), "Outside the Box: Rethinking ADD/ADHD in Children and Adults: A Practical Guide", American Psychiatric Association Publishing, Arlington, VA.

Cafferkey, K., Dundon, T., Winterton, J. and Townsend, K. (2020), "Different strokes for different folks: Group variation in employee outcomes to human resource management", Journal of Organizational Effectiveness: People and Performance, Vol. 7 No. 1, pp.1-19.

Cafferkey, K., Heffernan, M., Harney, B., Dundon, T. and Townsend, K. (2019), "Perceptions of HRM system strength and affective commitment: the role of human relations and internal process climate", The International Journal of Human Resource Management, Vol. 30 No. 21, pp.3026-3048. 
Cappelli, P. (2020), "Stop overengineering people management", Harvard Business Review,Vol. 98 No. 5, pp.55-63.

Carrero, J., Krzeminska, A. and Härtel, C. (2019), "The DXC technology work experience program: Disability-inclusive recruitment and selection in action", Journal of Management \& Organization, Vol. 25 No. 4, pp.535-542.

Chevallier, C., Kohls, G., Troiani, V., Brodkin, E.S. and Schultz, R.T. (2012), "The social motivation theory of autism", Trends in Cognitive Sciences, Vol. 16 No. 4, pp.231-239.

CIPD. (2018), Neurodiversity at Work, CIPD, London.

Davenport, T.H. and Prusak, L. (1998), Working Knowledge: How Organizations Manage What They Know, Boston, MA: Harvard Business Press, Boston, MA.

Davies, J. (2020), "Editorial. Implications for HRD practice and impact in the COVID-19 era", Human Resource Development Review, Vol. 19 No. 4, pp.335-338.

Deci, E.L. and Ryan, R.M. (2012), "Self-determination theory", Van Lange, P.A.M., Kruglanski, A.W. and Higgins, E.T. (Ed.s.), Handbook of Theories of Social Psychology, Sage, London, pp.416-436.

Doyle, N. (2020), "Neurodiversity at work: a biopsychosocial model and the impact on working adults", British Medical Bulletin, Vol. 135 No. 1, pp.108-125.

Dreaver, J., Thompson, C., Girdler, S., Adolfsson, M., Black, M.H. and Falkmer, M. (2020), "Success factors enabling employment for adults on the autism spectrum from employers' perspective", Journal of Autism Developmental Disorders, Vol. 50 No. 5, pp.1657-1667.

Garavan, T.N., Morley, M., Gunnigle, P. and Collins, E. (2001), "Human capital accumulation: The role of human resource development", Journal of European Industrial Training, Vol. 25 No. 2/3/4, pp.48-68.

García-Pérez, R.M., Lee, A. and Hobson, R.P. (2007), "On intersubjective engagement in autism: a controlled study of nonverbal aspects of conversation", Journal of Autism and Developmental Disorders, Vol. 37 No. 7, pp.1310-1322.

Gentry, T., Kriner, R., Sima, A., McDonough, J. and Wehman, P. (2015), "Reducing the need for personal supports among workers with autism using an iPod touch as an assistive technology: delayed randomized control trial", Journal of Autism and Developmental Disorders, Vol. 45 No. 3, pp.669-684.

Goldfarb, Y., Gal, E. and Golan, O.A. (2019), "Conflict of interests: a motivational perspective on special interests and employment success of adults with ASD", Journal of Autism and Developmental Disorders, Vol. 49 No. 9, pp.3915-3923.

Guest, D. E. (2017), "Human resource management and employee well-being: towards a new analytic framework", Human Resource Management Journal, Vol. 27 No. 1, pp.22-38.

Hackman, J.R. (1980), "Work redesign and motivation", Professional Psychology, Vol. 11 No. 3, pp.445-455.

Hagner, D. (2003), "Job development and job search assistance", Szymanski, E.M., and Parker, R.M. (Ed.s.), Work and Disability: Issues and Strategies in Career Development and Job Placement., 2nd edition, Pro-Ed, Austin, TX, pp.343-372. 
Hagner, D. and Cooney, B.F. (2005), "'I do that for everybody": Supervising employees with Autism", Focus on Autism and Other Developmental Disabilities, Vol. 20 No. 2, pp.91-97.

Härtel, C.E.J. and Fujimoto, Y. (2015), "Diversity is not the problem - openness to perceived dissimilarity is", Journal of the Australian and New Zealand Academy of Management, Vol. 6 No. 1, pp.14-27.

Harney, B. and Cafferkey, K. (2014), "The Role of the Line Manager in HRM-Performance Research". In: Machado, C. and Davim, P. (Ed.s) Work Organization and Human Resource Management. Switzerland: Springer International Publishing, pp.43-53.

Hayward, S.M., McVilly, K.R., and Stokes, M.A. (2019), "Autism and employment: what works", Research in Autism Spectrum Disorders, Vol. 60, pp.48-58.

Heasman B. and, Gillespie A. (2019), "Neurodivergent intersubjectivity: distinctive features of how autistic people create shared understanding", Autism, Vol. 23 No. 4, pp.910-921.

Hedley, D., Cai, R., Uljarević, M., Wilmot, M., Spoor, J., Richdale, A. and Dissanayake, C. (2018), "Transition to work: perspectives from the autism spectrum", Autism, Vol. 22, pp.528-541.

Hidegh, A.L. and Csillag, S. (2013), "Toward 'mental accessibility': changing the mental obstacles that future human resource management practitioners have about the employment of people with disabilities", Human Resource Development International, Vol. 16 No. 1, pp.22-39.

Hurley-Hanson A.E., Giannantonio C.M. and, Griffiths A.J. (2020), "The stigma of autism", Hurley-Hanson A.E., Giannantonio C.M. and Griffiths A.J. (Ed.s.), In: Autism in the Workplace. Palgrave Explorations in Workplace Stigma. Palgrave Macmillan, Cham, pp.21-45.

Jaarsma, P. and Welin, S. (2012), "Autism as a natural human variation: reflections on the claims of the neurodiversity movement", Health Care Analysis, Vol. 20 No. 1, pp.20-30.

Jiang, K., Hu, J., Liu, S. and Lepak, D.P. (2017), "Understanding employees' perceptions of human resource practices: effects of demographic dissimilarity to managers and coworkers", Human Resource Management, Vol. 56 No. 1, pp.69-91.

Jiang, K., Lepak, D.P., Hu, J. and Baer, J.C. (2012), "How does human resource management influence organisational outcomes? A meta-analytic investigation of mediating mechanisms", Academy of Management Journal, Vol. 55 No. 6, pp.1264-1294.

Johnson, K.R., Ennis-Cole, D. and Bonhamgregory, M. (2020), "Workplace success strategies for employees with autism spectrum disorder: a new frontier for human resource development", Human Resource Development Review, Vol. 19 No. 2, pp.122-151.

Jones, G.E. (1997), "Advancement opportunity issues for persons with disabilities", Human Resources Management Review, Vol. 7 No. 1, pp.56-76.

Kellner, A., Cafferkey, K. and Townsend, K. (2019), "Ability, Motivation and Opportunity theory: a formula for employee performance?", Townsend, K., Cafferkey, K., McDermott, A.M. and Dundon, T. (Ed.s.), Elgar Introduction to Theories of Human Resources and Employment Relations, Edward Elgar Publishing, Cheltenham, pp.311323. 
Kelly, S. and Senior, A. (2021), "Towards a feminist parental ethics", Gender Work \& Organization.

Kim, S., Egan, T.M., Kim, W. and Kim, J. (2013), "The impact of managerial coaching behavior on employee work-related reactions", Journal of Business and Psychology, Vol. 28 No. 3, pp.315-330.

Kinnie, N., Hutchinson, S., Purcell, J., Rayton, B. and Swart, J. (2005), "Satisfaction with HR practices and commitment to the organisation: Why one size does not fit all", Human Resource Management Journal, Vol. 15 No. 4, pp.9-29.

Knapp, M., Romeo, R. and Beecham, J. (2009), "Economic cost of autism in the UK", Autism, Vol. 13 No. 3, pp.317-336.

Krzeminska, A., Austin, R., Bruyère, S. and Hedley, D. (2019), "The advantages and challenges of neurodiversity employment in organizations", Journal of Management \& Organization, Vol. 25 No. 4, pp.453-463.

Lever, M. (2016), The Autism Employment Gap: Too Much Information in the Workplace, The National Autistic Society, London.

Luu, T.T. (2018), "Engaging employees with disabilities in Vietnamese business context", Employee Relations, Vol. 40 No. 5, pp.822-847.

Maroto, M. and Pettinicchio, D. (2015), "Twenty-five years after the ADA: situating disability in America's system of stratification", Disability Studies Quarterly, Vol. 35 No. 3, pp.134.

Mastroianni, K. and Storberg-Walker, J. (2014), "Do work relationships matter? Characteristics of workplace interactions that enhance or detract from employee perceptions of well-being and health behaviors", Health Psychology and Behavioral Medicine, Vol. 2 No. 1, pp.798-819.

Mpofu, E., Tansey, T., Mpofu, N., Tu, W.M. and, \& Li, Q. (2019), "Employment practices with people with autism spectrum disorder in the digital age", Potgieter, I.L., Ferreira, N., Coetzee, M. (Ed.s), Theory, Research and Dynamics of Career Wellbeing, Springer, Cham, pp.309-326.

Müller, E., Schuler, A., Burton, A.B. and Yates, G.B. (2003), "Meeting the vocational support needs of individuals with Asperger syndrome and other autism spectrum disabilities", Journal of Vocational Rehabilitation, Vol. 18 No. 3, pp.163-175.

Obeidat, S.M., Mitchell, R. and Bray, M. (2016), "The link between high performance work practices and organizational performance: empirically validating the conceptualization of HPWP according to the AMO model", Employee Relations, Vol. 38 No. 4, pp.578-595.

Parr, A.D., Hunter, S.T. and Ligon, G.S. (2013), "Questioning universal applicability of transformational leadership: Examining employees with autism spectrum disorder", The Leadership Quarterly, Vol. 24 No. 4, pp.608-622.

Patton, E. (2019), "Autism, attributions and accommodations: overcoming barriers and integrating a neurodiverse workforce", Personnel Review, Vol. 48 No. 4, pp.915-934.

Philips, B.N., Deiches, J., Morrison, B., Chan, F. and Bezyak, J.L. (2016), "Disability diversity training in the workplace: systematic review and future directions", Journal of Occupational Rehabilitation, Vol. 26 No. 3, pp.264-275. 
Premeaux, S.F. (2001), "Impact of applicant disability on selection: the role of disability type, physical attractiveness, and proximity", Journal of Business and Psychology, Vol. 16 No. 2, pp.291-298.

Procknow, G. and Rocco, T. (2016), "The unheard, unseen, and often forgotten: an examination of disability in the human resource development literature", Human Resource Development Review, Vol. 15 No. 4, pp.379-403.

Purcell, J., Hutchinson, S., Kinnie, N., Rayton, B. and Swart, J. (2003), Understanding the People and Performance Link: Unlocking the Black Box, CIPD Publishing, London.

Randel, A.E., Galvin, B.M., Shore, L.M., Ehrhart, K.H., Chung, B.G., Dean, M.A. and Kedharnath, U. (2018), "Inclusive leadership: realizing positive outcomes through belongingness and being valued for uniqueness", Human Resource Management Review, Vol. 28 No. 2, pp.190-203.

Richards, J., Sang, K., Marks, A., and Gill, S. (2019), "I've found it extremely draining", Personnel Review, Vol. 48 No. 7, pp.1903-1923.

Roberge, M.-É. and van Dick, R. (2010), "Recognizing the benefits of diversity: when and how does diversity increase group performance?", Human Resource Management Review, Vol. 20 No. 4, pp.295-308.

Scott, M., Falkmer, M., Girdler, S. and Falkmer, T. (2015), "Viewpoints on factors for successful employment for adults with autism spectrum disorder", PloS one, Vol. 10 No. 10.

Scott, M., Milbourn, B., Falkmer, M., Black, M., Bölte, S., Halladay, A., Lerner, M., Taylor, J.L. and Girdler, S. (2019), "Factors impacting employment for people with autism spectrum disorder: a scoping review", Autism, Vol. 23 No. 4, pp.869-901.

Scott-Van Zeeland, A.A, Dapretto, M, Ghahremani, D.G., Poldrack, R.A. and Bookheimer, S.Y. (2010), "Reward processing in autism", Autism Research, Vol. 3 No. 2, pp.53-67.

Shore, L.M., Cleveland, J.N. and Sanchez, D. (2018), "Inclusive workplaces: a review and model", Human Resource Management Review, Vol. 28 No. 2, pp.176-189.

Silvers, A. (2011), "Better than new! Ethics for assistive technologists" Oishi, M., Mitchell, I. and Van der Loos, H.(Ed.s), Design and Use of Assistive Technology, Springer, Cham, pp.3-15.

Szulc, J.M. (2020), "Beyond quid pro quo: good soldiers and characteristics of their helping behaviours", Personnel Review.

Tomasello, M., Carpenter, M., Call, J., Behne, T. and Moll, H. (2005), "Understanding and sharing intentions: The origins of cultural cognition", Behavioral and Brain Sciences, Vol. 28 No. 5, pp.675-735.

Tomczak, M.T. (2020), "Employees with autism spectrum disorders in the digitized work environment: perspectives for the future", Journal of Disability Policy Studies.

Tomczak, M.T., Wójcikowski, M., Pankiewicz, B., Łubiński, J., Majchrowicz, J., Majchrowicz, D., Walasiewicz, A., Kiliński, T. and Szczerska, M. (2020), Stress monitoring system for individuals with autism spectrum disorders. IEEE Access, Vol. 8, pp.22823-22834. 
Tomczak, M.T., Wójcikowski, M., Listewnik, P., Pankiewicz, B., Majchrowicz, D. and Jędrzejewska-Szczerska, M. (2018), "Support for Employees with ASD in the Workplace Using a Bluetooth Skin Resistance Sensor ${ }^{-}$A Preliminary Study", Sensors, Vol. 18 No. 10, pp.3530-3544.

Torraco, R.J. (2005), "Work design theory: A review and critique with implications for human resource development", Human Resource Development Quarterly, Vol. 16 No. 1, pp.85109.

Troth, A.C. and Guest, D.E. (2020), "The case for psychology toin human resource management research", Human Resource Management Journal, Vol. 30 No. 1, pp.34-48.

Vogus, T.J. and Taylor, J.L. (2018), "Flipping the script: bringing an organizational perspective to the study of autism at work", Autism, Vol. 22 No. 5, pp.514-516.

Walsh, E., Holloway, J., McCoy, A. and Lydon, H. (2017), "Technology-Aided Interventions for Employment Skills in Adults with Autism Spectrum Disorder: A Systematic Review", Review Journal of Autism and Developmental Disorders, Vol. 4 No. 1, pp.1225 .

Whelpley, C.E., Banks, G.C., Bochantin, J.E. and Sandoval, R. (2020), "Tensions on the spectrum: an inductive investigation of employee and manager experiences of autism", Journal of Business and Psychology.

Wiklund, J., Hatak, I., Lerner, D.A., Verheul, I., Thurik, R. and Antshel, K. (2020), "Entrepreneurship, clinical psychology, and mental health: an exciting and promising new field of research", Academy of Management Perspectives, Vol. 34, pp.291-295.

Wiklund, J., Hatak, I., Patzelt, H. and Shepherd, D.A. (2018), "Mental disorders in the entrepreneurship context: when being different can be an advantage", Academy of Management Perspectives, Vol. 32, No. 2, pp.182-206.

Winterton, J. and Cafferkey, K. (2019), "Revisiting human capital theory: progress and prospects", Townsend, K., Cafferkey, K., McDermott, A.M. and Dundon, T. (Ed.s), Elgar Introduction to Theories of Human Resources and Employment Relations.Edward Elgar Publishing, Cheltenham, pp.218-234. 
Dimensions for Neurodivergent Individuals

\section{Systems-Wide Dimensions}

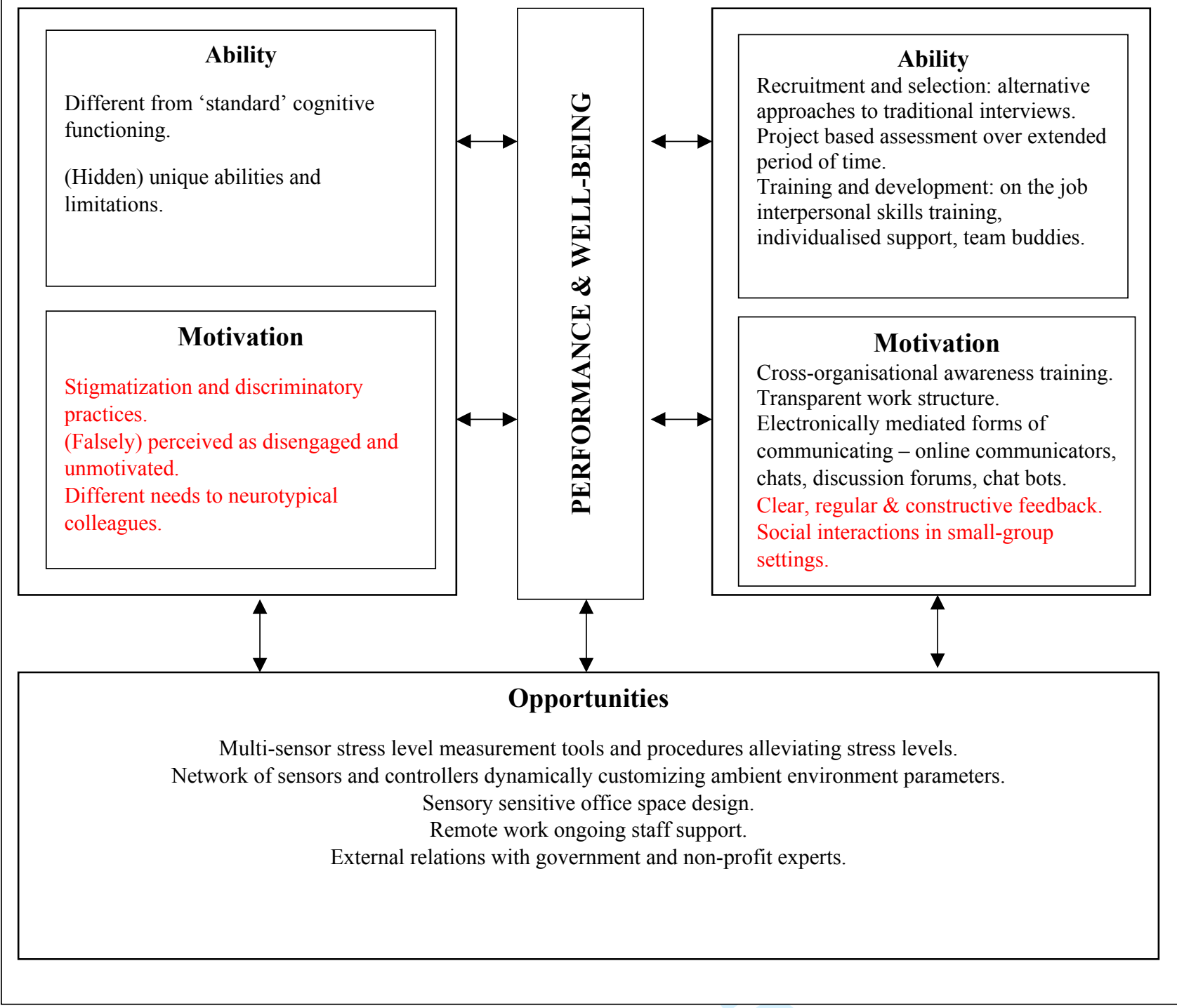

Figure 1. Dynamic model of neurodivergent AMO for HRM research.

Adapted from: Kellner et al. (2019) 
Table I. Neurodivergent individuals' abilities

\begin{tabular}{lll}
\hline CONDITION & $\begin{array}{l}\text { PROSPECTIVE WORKPLACE } \\
\text { CONTRIBUTIONS }\end{array}$ & $\begin{array}{l}\text { PROSPECTIVE WORKPLACE } \\
\text { CHALLENGES }\end{array}$ \\
\hline ADHD & $\begin{array}{l}\text { Creativity, hyper-focus, energy and } \\
\text { passion, authenticity, } \\
\text { entrepreneurialism }\end{array}$ & $\begin{array}{l}\text { Impulsive temper outbursts, hyperactivity, } \\
\text { low frustration threshold, poor listening } \\
\text { skills, difficulty with maintaining } \\
\text { employment, difficulty with team-work }\end{array}$ \\
\hline $\begin{array}{l}\text { Autism } \\
\text { Conditions }\end{array}$ & $\begin{array}{l}\text { Concentration, fine detail } \\
\text { processing, memory, honesty, } \\
\text { sensory awareness }\end{array}$ & $\begin{array}{l}\text { Over- and under-sensitive to light, noise, } \\
\text { touch, temperature, difficulty with speech } \\
\text { and language, difficulty with stress } \\
\text { control, poor listening skills }\end{array}$ \\
\hline DCD/Dyspraxia & $\begin{array}{l}\text { Verbal skills, empathy, intuition, } \\
\text { honesty }\end{array}$ & $\begin{array}{l}\text { Difficulties with planning, movements, } \\
\text { coordination, poor spatial awareness, over- } \\
\text { and under-sensitive to light, noise, touch, } \\
\text { temperature, difficulty with speech and } \\
\text { language, poor listening skills }\end{array}$ \\
& & $\begin{array}{l}\text { Difficulty with number concepts and } \\
\text { calculations, poor listening skills }\end{array}$ \\
\hline Dyscalculia & $\begin{array}{l}\text { Verbal skills, innovative thinking, } \\
\text { creativity }\end{array}$ & $\begin{array}{l}\text { Difficulty with words: reading, writing, } \\
\text { spelling, speaking, listening; preference for } \\
\text { non-linear thought, distractibility, poor } \\
\text { listening skills }\end{array}$ \\
\hline Dyslexia & $\begin{array}{l}\text { Visual thinking, creativity, 3D } \\
\text { entrepreneurialism }\end{array}$ & $\begin{array}{l}\text { Verbal and physical tics, poor listening } \\
\text { skills }\end{array}$ \\
& $\begin{array}{l}\text { Observational skills, cognitive } \\
\text { control, creativity, hyper-focus, } \\
\text { innovative thinking }\end{array}$ &
\end{tabular}

Adapted from: Doyle (2020) 